\title{
The discovery of the earliest specialised Middle Neolithic pottery workshop in western Thessaly, central Greece
}

\author{
Athanasia Krahtopoulou ${ }^{1, *}$, Anastasia Dimoula ${ }^{2}$, Alexandra Livarda ${ }^{3}$ \\ $\&$ Niki Saridaki ${ }^{4}$
}

Disparity in recorded Neolithic activity between the eastern and western Thessaly plain in central Greece is being redressed by the 'Long Time No See' landscape project. A recently discovered pottery kiln complex at Magoula Rizava tell site offers exciting new evidence for intra-regional pottery production and circulation during the Middle Neolithic period.

\section{Introduction}

Test excavations undertaken by the Ephoreia of Antiquities of Karditsa in June 2017 at the tell site of Magoula Rizava in Greece revealed the remains of an exceptionally rare Neolithic pottery workshop. The tell is situated on the western Thessalian plain, near the city of Karditsa in central Greece (Figure 1). Thessaly has been traditionally perceived as the 'cradle' of the Greek Neolithic (seventh to fourth millennia BC) and a key area for understanding the Neolithisation of Europe. Eastern Thessaly exhibits an exceptional density of Neolithic settlements. Conversely, the western plain was considered to be sparsely occupied. This picture, however, has been altered drastically by the new interdisciplinary project 'Long Time No See' (LTNS), which focuses on investigating the western Thessalian landscape. LTNS has already located an unprecedented and still growing number of Neolithic sites. This has proven unequivocally that the previously observed pattern was due to a lack of rigorous, targeted research and to recent, large-scale landscape modifications that have dramatically changed the physical landscape and devastated the archaeological record of the area (Orengo et al. 2015). In this context, nearly half of Magoula Rizava had been levelled illegally.

\section{The pottery workshop}

Surface pottery finds date the use of Magoula Rizava firmly from the Early to Middle Neolithic (c. 6700-5300 BC). Test excavations explored the archaeological deposits exposed

1 Ephoreia of Antiquities of Karditsa, Hellenic Ministry of Culture \& Sports, 1 Loukianou Street, 43100 Karditsa, Greece

2 School of History \& Archaeology, Aristotle University of Thessaloniki, 54124 Thessaloniki, Greece

3 Department of Classics \& Archaeology, University of Nottingham, University Park, Nottingham NG7 2RD, UK

4 School of History \& Archaeology, Aristotle University of Thessaloniki, 54124 Thessaloniki, Greece

* Author for correspondence (Email: akrachtopoulou@culture.gr)

(C) Antiquity Publications Ltd, 2018

ANTIQUITY 92 362, e5 (2018): 1-7

https://doi.org/10.15184/aqy.2018.54 


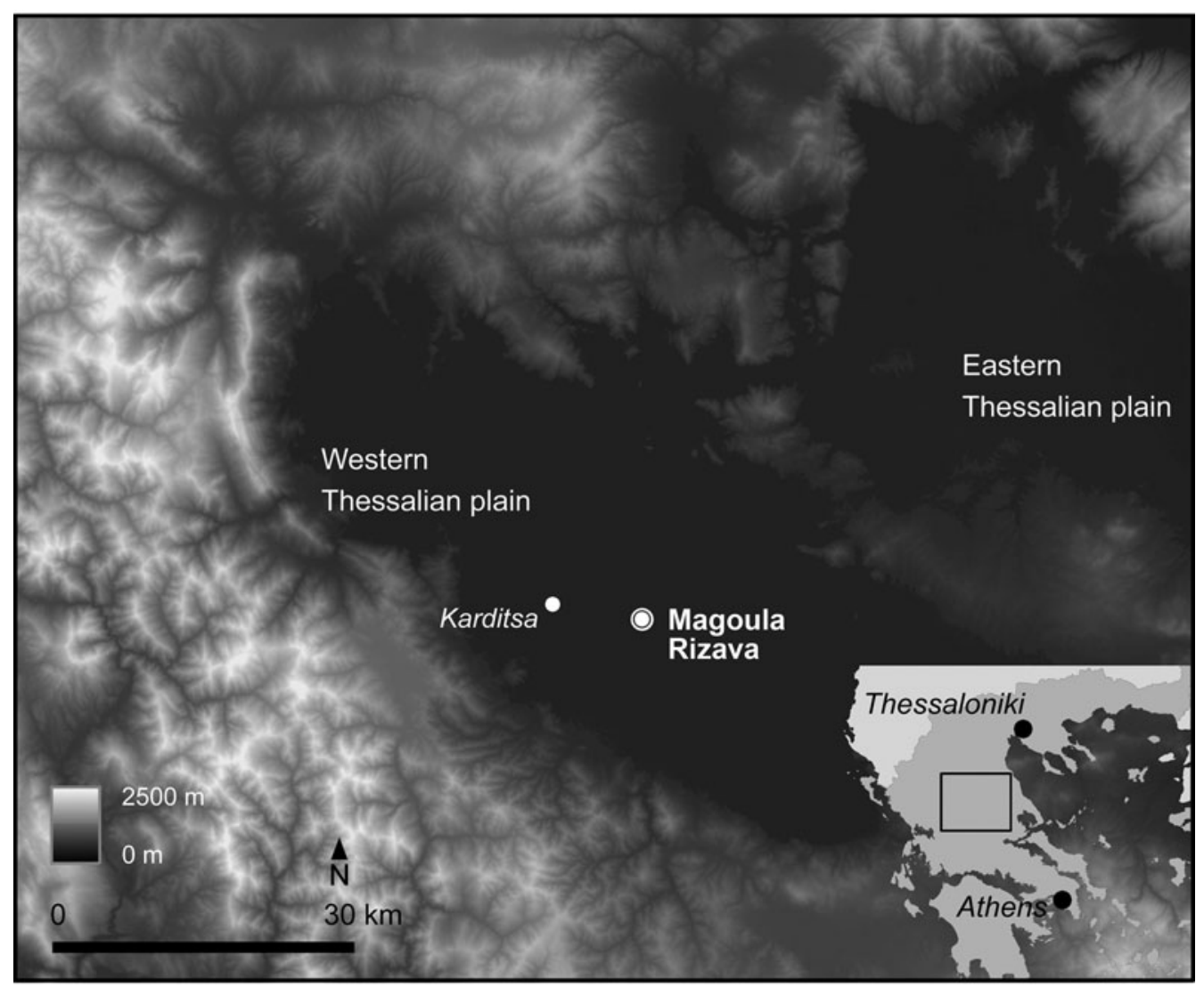

Figure 1. Location map.

by modern levelling activities. A group of at least six differentially preserved, closely spaced, heavily burnt, closed ovens (O1-6), enclosed by a mud-brick wall, were uncovered at the western edges of the tell (Figure 2). Successive ovens seem to have been built or rebuilt in the same confined area, often incorporating elements of earlier structures.

The latest and best-preserved oven (O1) offers valuable information on form and construction techniques (Figures $2 \& 3$ ). This oven $(\mathrm{O} 1)$ was built on a raised platform. The floor $(1.6 \times 1.25 \mathrm{~m})$ is preserved, as are the lower part of the superstructure (wall thickness: $0.28 \mathrm{~m}$ ) and an opening (width: $0.54 \mathrm{~m}$ ) at its front. A lateral bench extends on the opening side. Many scattered wall parts and the top of the front opening (Figure 4) indicate the collapse of a fully domed structure. The vault was made by the complex layering of coarse clay_rich in organic material_ and covered by white plaster. A clay 'table' $(0.23$ $\times 0.21 \times 0.15 \mathrm{~m}$ ) was set on the raised platform in front of the structure (Figure 3 ). The domes of two earlier ovens (O2 \& O3) were also partially preserved, while another three ovens (O4-6) had been heavily damaged in antiquity (Figure 2).

Immediately to the west of the enclosing wall was a narrow space separating this group of structures from another, which yielded similar remains and evidence of heavy burning, but was only partially excavated. This corridor-like space was used for discarding large quantities (C) Antiquity Publications Ltd, 2018 


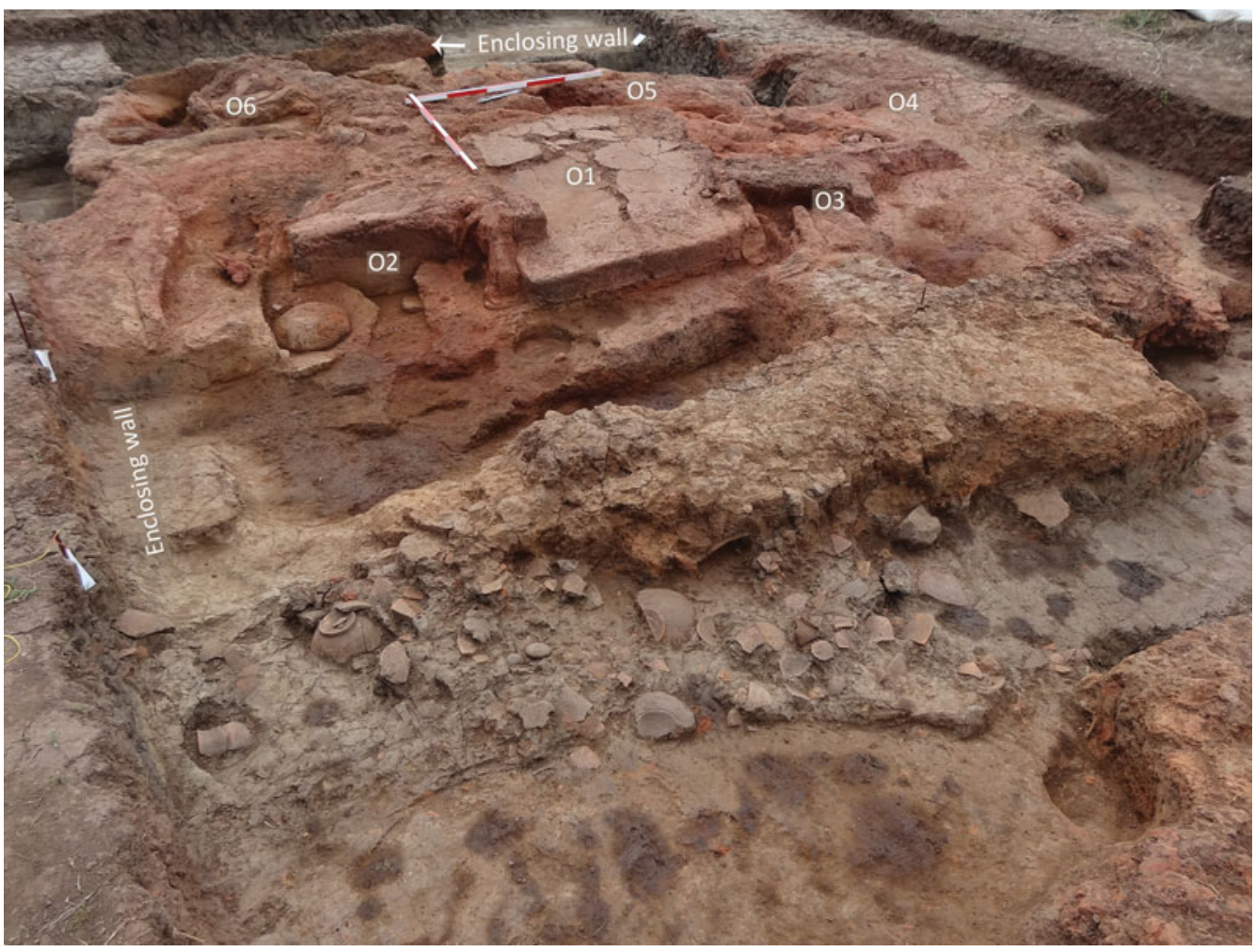

Figure 2. The test excavation, the group of structures unearthed and the 'scraped' pottery discard context; view from the west.

of pottery, raw clay, fired and unfired clay lumps bearing evidence of processing (Figure 5), fragments of heat-exposed limestone, several burnishing and grinding stones, a few chipped stone-tools, a miniature ceramic vessel and a clay 'stamp' (Figure 2). Preliminary assessment of the pottery assemblage associated with the oven complex showed that more than 90 per cent belongs to a particular Middle Neolithic painted category known as 'scraped' ware, of which the assemblage included all known shapes and sizes (Figure 6). A similar discard context was also identified immediately to the east of the enclosing wall.

Archaeobotanical analysis of the entire sedimentary matrix (196 litres) of the west discard context identified only 24 charred remains, comprising mostly barley grains and wild seeds. A radiocarbon date on short-lived barley seeds yielded an age of 5797-5664 cal BC (BETA476070), placing this discrete discard event well into the Middle Neolithic period. The complex of ovens is not concomitant with habitation areas; rather, it probably represents an area of repetitive ceramic firing activities associated with groups of vaulted furnaces, dumps of pottery and related tools and raw materials.

\section{Discussion and future research}

Closed thermal structures are quite common inside and outside of Neolithic houses (Kalogiropoulou 2014), with most being interpreted as cooking installations

(C) Antiquity Publications Ltd, 2018 


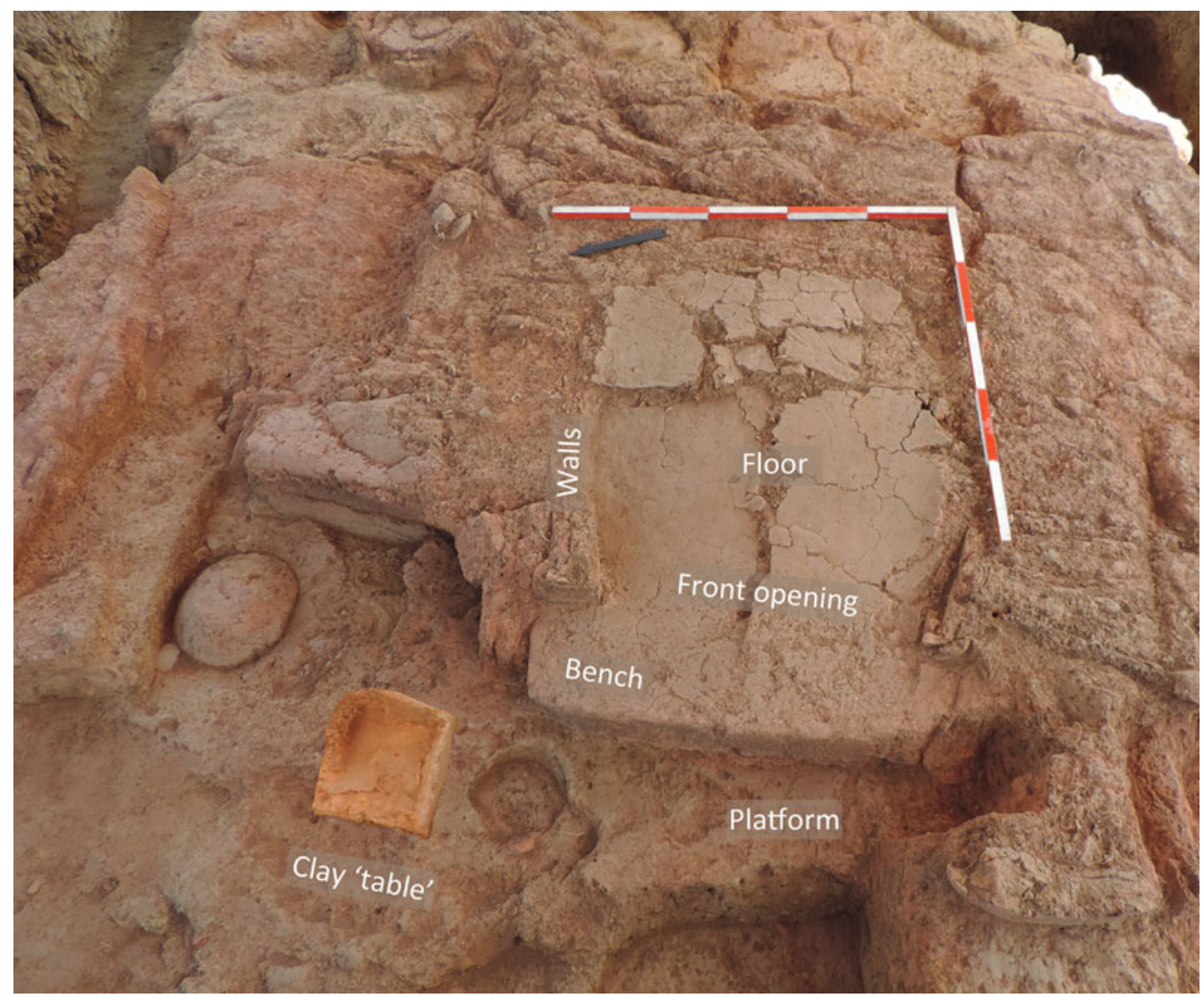

Figure 3. Clay 'table' in front of oven O1; view from the north-west.

(Papadopoulou \& Prévost-Dermarkar 2016). Moreover, previous research has widely assumed that Middle Neolithic pottery was fired in open fires or pits (Maniatis \& Tite 1981). Interestingly, a number of well-preserved Middle Neolithic combustion structures have been unearthed recently at Magoula Imvrou Pigadi, situated approximately $20 \mathrm{~km}$ south-east of Magoula Rizava (Kyparissi-Apostolika 2012). These structures share many morphological features with those described above and are interpreted as pottery kilns.

Detailed macroscopic and pilot petrographic analyses of the LTNS surface ceramic assemblage indicate that the dominant Middle Neolithic monochrome 'red-slipped' and the common 'impresso' wares were locally produced and exhibited a low degree of circulation among the sites of the region. The 'red on cream' painted ware was also locally produced but not circulated. In contrast, the Thessaly 'scraped' ware vessels were produced locally and circulated widely across the central-western plain, and comprise a strikingly homogeneous, high-fired fabric, implying a rather standardised, 'specialised' manufacturing and firing process.

The implications of the new data presented here are far-reaching and significant. Available evidence offers a snapshot in the life of a ware-specific Middle Neolithic (C) Antiquity Publications Ltd, 2018 


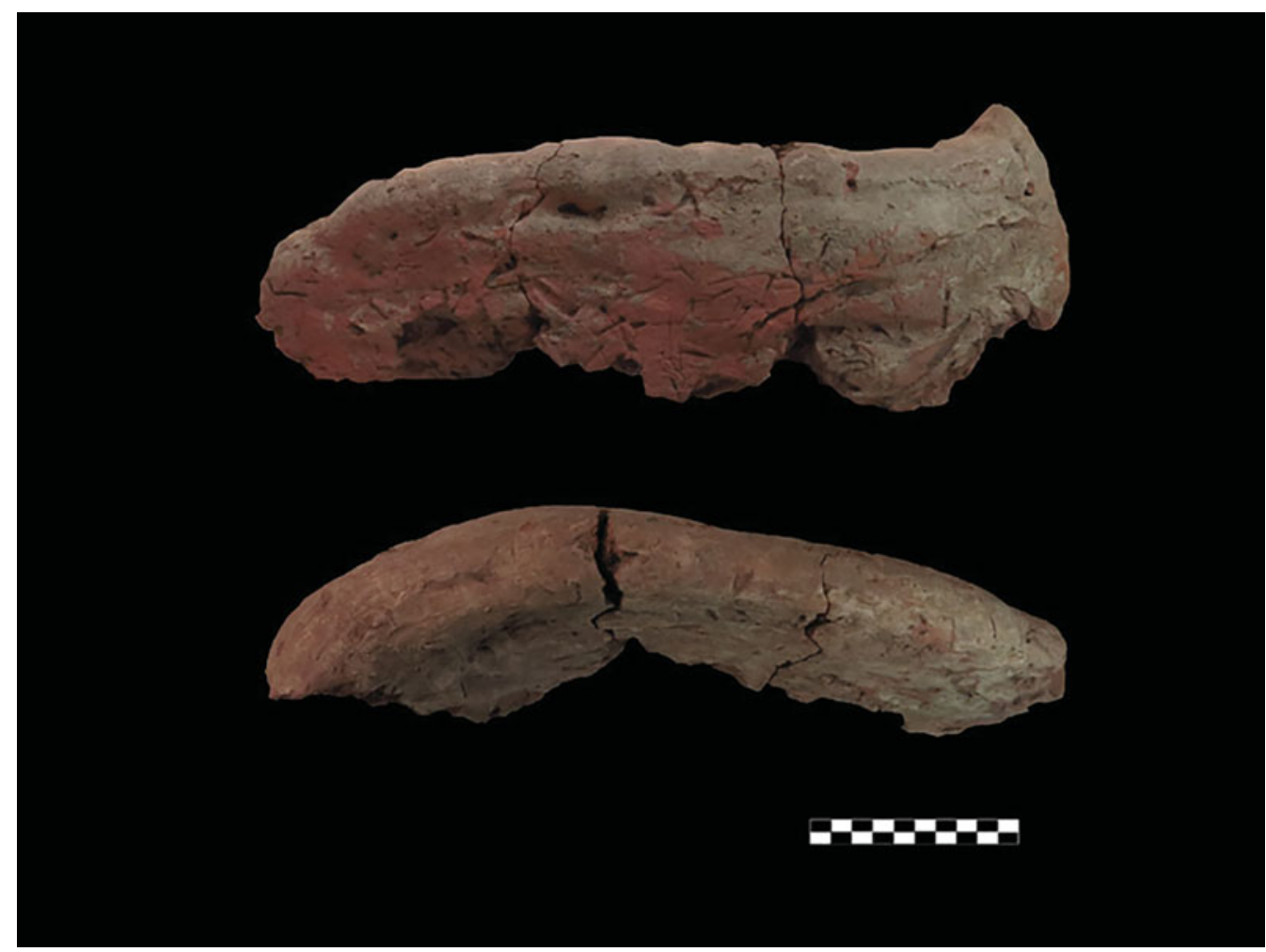

Figure 4. The white-plastered top of the front opening of oven O1. Back (top) and front (bottom) view.

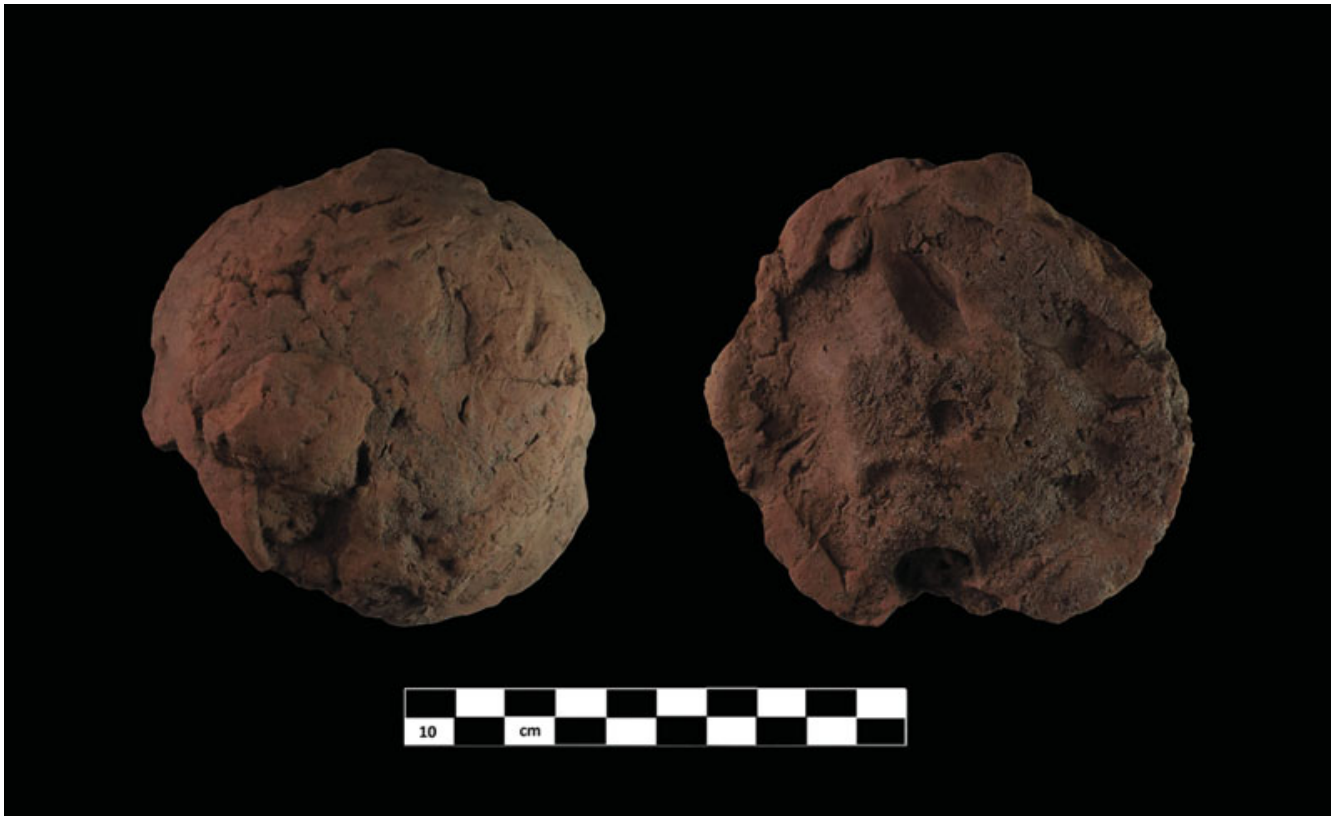

Figure 5. A possible base of an unfinished vessel.

(C) Antiquity Publications Ltd, 2018 


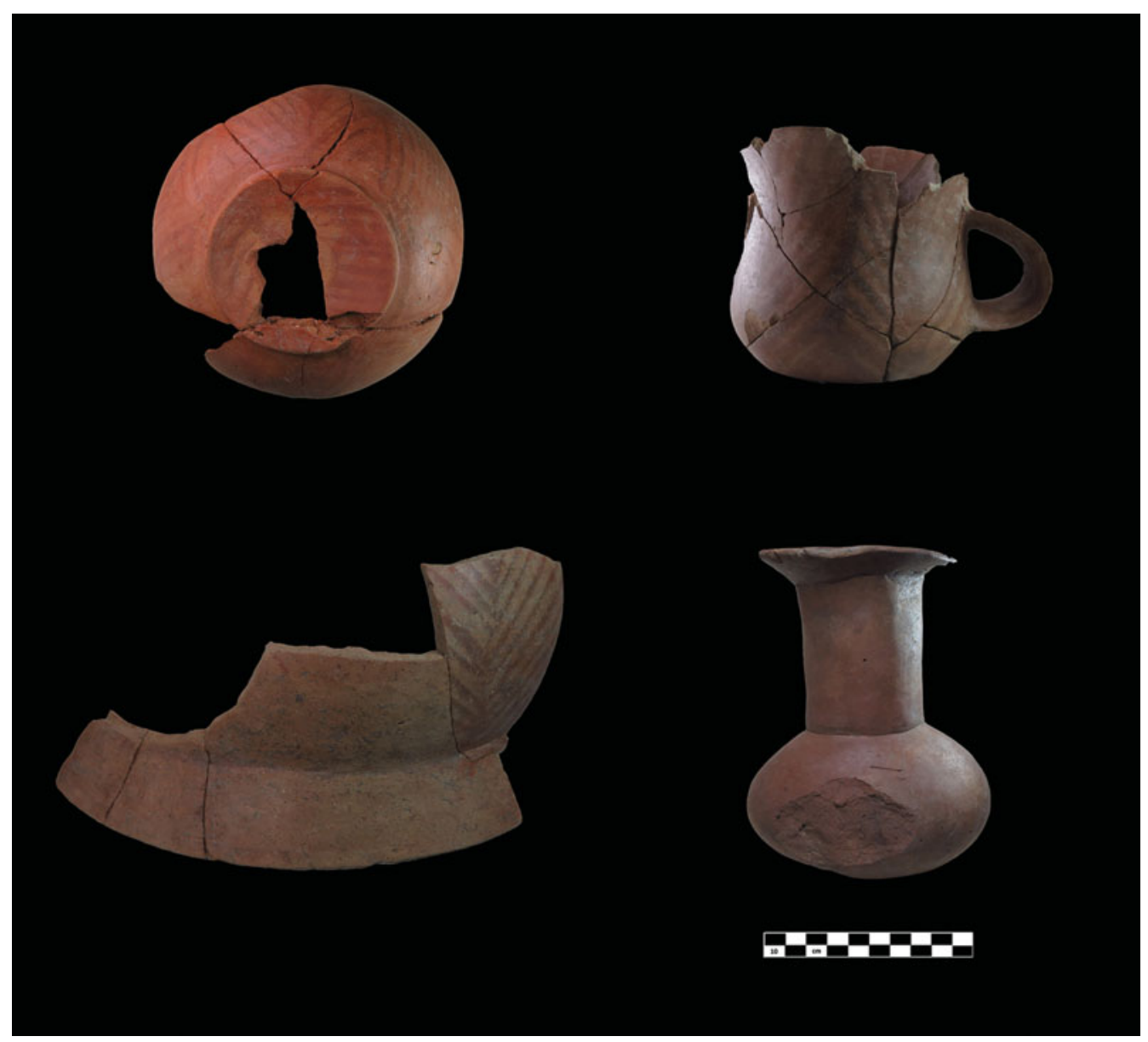

Figure 6. Characteristic 'scraped' ware vessels during refitting.

pottery workshop that may have acted as a regional production centre for 'scraped' ware pottery. Future detailed investigation of the excavated area involving bioarchaeological and geoarchaeological analyses, combined with integrated macroscopic, petrographic and chemical analyses of pottery from the production site and from the Middle Neolithic sites identified by LTNS, will offer, for the first time, robust evidence of intra-regional pottery production and circulation. These investigations will also provide a unique opportunity to structure a fresh narrative, which is essential to understand and contextualise the social use of space and practices operating in Middle Neolithic western Thessaly and beyond.

\section{Acknowledgements}

Panos Barboutis, Kostas Palaiochoritis, Thomas Pappas and Vaggelis Skordas offered their enthusiasm, skills and hard labour; and Manthos Besios inspired the work. Lena Tasiopoulou drew; Apostolia Mastora conserved;

(C) Antiquity Publications Ltd, 2018 
Alexis Tsiogas photographed; Hector Orengo provided Figure 1; and Vangelio Kiriatzi commented. We are most grateful to all of them. INSTAP supported preliminary post-excavation analysis.

\section{References}

Kalogiropoulou, E. 2014. In search of social identities: the contribution of thermal structures in the organisation of space in neolithic Macedonia, in E. Stefani, E. Merousis \& A. Dimoula (ed.) 1912-2012. A century of research in prehistoric Macedonia. International conference proceedings, Archaeological Museum of Thessaloniki, 22-24 November 2012: 359-72. Thessaloniki: Ziti.

Kyparissi-Apostolika, N. 2012. Indications of the presence of Middle Neolithic pottery kilns at Magoula Imvrou Pigadi, SW Thessaly, Greece. Documenta Praehistorica XXXIX: 433-42. https://doi.org/10.4312/dp.39.31

Maniatis, Y. \& M.S. Tite. 1981. Technological examination of Neolithic-Bronze Age pottery from Central and south-east Europe and from the Near East. Journal of Archaeological Science 8: 59-76. https://doi.org/10.1016/0305-4403(81)90012-1
Orengo, H.A., A. Krahtopoulou,

A. Garcia-Molsosa, K. Palaiochoritis \& A. Stamati. 2015. Photogrammetric re-discovery of the hidden long-term landscapes of western Thessaly, central Greece. Journal of Archaeological Science 64: 100-109. https://doi.org/10.1016/j.jas.2015.10.008

Papadopoulou, E. \& S. Prévost-Dermarkar. 2016. 'Il n'y a pas de cuisine sans feu': une approche des techniques culinaires au Néolithique et à l'Âge du Bronze Ancien à travers les structures de combustion en Grèce du Nord, in C. Mee \& J. Renard (ed.) Cooking up the past: food and culinary practices in the Neolithic and Bronze Age Aegean: 123-35. Oxford: Oxbow. 